\title{
Dynamic Splitting Tensile Properties and Failure Mechanism of Layered Slate
}

\author{
Yunsi Liu $\mathbb{D}^{1,2}$ Chushao He, ${ }^{1,2}$ Shiming Wang, ${ }^{2}$ Yaxiong Peng, ${ }^{1,2}$ and Yong Lei ${ }^{1,2}$ \\ ${ }^{1}$ Hunan Provincial Key Laboratory of Geotechnical Engineering for Stability Control and Health Monitoring, \\ Hunan University of Science and Technology, Xiangtan, China \\ ${ }^{2}$ School of Civil Engineering, Hunan University of Science and Technology, Xiangtan, China \\ Correspondence should be addressed to Yunsi Liu; liuyunsi@sohu.com
}

Received 1 January 2020; Revised 30 April 2020; Accepted 11 July 2020; Published 17 August 2020

Academic Editor: Yann Malecot

Copyright (c) 2020 Yunsi Liu et al. This is an open access article distributed under the Creative Commons Attribution License, which permits unrestricted use, distribution, and reproduction in any medium, provided the original work is properly cited.

\begin{abstract}
Dynamic tensile failure is one of the main failure modes of layered rock masses during the excavation of underground engineering. This study investigates the influence of loading rate and layered inclination angle on the mechanical properties and failure mechanisms of layered slate using a split-Hopkinson pressure bar system and high-speed cameras. The results show that, overall, the dynamic elastic modulus $E$, postpeak stress reduction rate $K$, and failure load of the discs with the 7 tested bedding angles increase with the increasing loading rate. A nonlinear formula is proposed to describe the relationship between loading rate and failure load for the 7 tested inclination angles. As the inclination angle of the bedding planes increases from $0^{\circ}$ to $90^{\circ}$, both the static and dynamic failure loads of the slate increased. However, with increasing loading rate, the anisotropic influence coefficient $\mathrm{N}$ ranges from 3.25 under the static load to 1.35 under the dynamic load, and the bedding effect gradually decreases. From the dynamic Brazilian splitting tests, the failure of the discs is mainly observed along the bedding planes when the inclination angle is less than or equal to $45^{\circ}$. Failure of the discs mainly occurs along the centre of the disc and previously intact planes when the inclination angle is greater than $60^{\circ}$. This study provides significant data to evaluate the mechanical properties and failure mechanisms of layered rock and the safety and stability of layered rock under dynamic loading.
\end{abstract}

\section{Introduction}

Layered rock masses [1-10], such as slate, shale, coal, and sandstone, are commonly employed in engineering construction. In civil air defence, transportation, mining, and other fields, the dynamics of layered rock masses are widely investigated, especially in terms of the rock mass destruction and stability issues involved in the excavation of underground chambers [11-13]. In the process of rock drilling and blasting, a series of problems arise, such as dynamic disaster caused by mechanical disturbance and blasting impact and a much lower effective energy of rock breaking than the total input energy [14].

Tensile failure is one of the main failure modes in rock mass engineering. Especially under dynamic disturbance, the original cracks in the rock mass are affected by the stress wave, causing tensile failure [15-18]. It should be noted that the loads caused by hazardous events such as an earthquake or a blast are highly transient in nature, generating high strain rates in the rock, and the strain rate caused by a blast may reach up to $10^{4} / \mathrm{sec}$ [19]. The SHPB system can effectively simulate rock mass strain rates from $10^{-4}$ to $10^{3} / \mathrm{sec}$ [20]. The Brazilian splitting test is an indirect method of testing the dynamic tensile strength of a rock mass [21] and is one of the most accepted methods in international rock mechanics [22]. The SHPB system can effectively determine the tensile strength of a rock mass under impact load [23]. Shortly after impact, the pattern of the dynamic stress distribution in specimens has been observed to be symmetric and similar to that of the static loading; cracks first initiate at the centre of the disc and subsequently propagate along the loading diameter [24].

Over the past few years, the dynamic tensile test has mainly been used to study isotropic rock, such as red 
sandstone [25] and granite [26]. The research shows that, under the SHPB dynamic tensile test, the disc of the sample is always split along the centre of the disc into two halves, and the tensile strength and elastic modulus of the rock increase with increasing loading rate. However, the bedding planes of layered rock masses are weak surfaces, and the strength of layered rock is much lower than that of intact rock. The different angles between the bedding plane and the load have a great influence on the tensile strength $[27,28]$, elastic modulus [29, 30], and failure mode [31] of the rock.

In this work, Brazilian disc specimens of slate were tested to determine stress-strain curves and strengths under different loading rates and layer orientations by using a SHPB system. A high-speed camera recorded the entire process of slate splitting in the SHPB system. Based on these techniques, we analysed the dynamic failure load, elasticity modulus, and stress-strain law of slate under the combined action of layer orientation and loading rate and the failure law of slate under different layer orientations.

\section{Sample Preparation and Testing Methodology}

2.1. Specimen Preparation. The rock samples were all slate from a region in the southwest of Huaihua city, Hunan, China. The rock samples were extracted by a $50 \mathrm{~mm}$ drill bit inserted parallel to the layer orientation. The diameter of the specimen is thus approximately $50 \mathrm{~mm}$, and the thickness is approximately equal to the specimen radius. The thickness of the specimen is less than or equal to $0.025 \mathrm{~mm}$. The specimen's end faces are flat to within $0.25 \mathrm{~mm}$ and parallel to within $0.25^{\circ}$ [21].

2.2. Test Programme. Brazilian splitting tests are divided into two types: static loading and dynamic loading. The static Brazilian splitting test was carried out with the RMT-150C rock test machine developed by Wuhan Geotechnical Institute. The loading rate was controlled at $0.01 \mathrm{~mm} / \mathrm{s}$ by a computer. The stress and strain curves were directly collected by the sensor and recorded by the computer. The dynamic Brazilian splitting test was completed in the SHPB system, and the loading rate was controlled by high-pressure nitrogen gas during the test. The angle between the layer and the loading direction was defined as the inclination angle. In this test, 7 different inclination angles were investigated: $0^{\circ}$, $15^{\circ}, 30^{\circ}, 45^{\circ}, 60^{\circ}, 75^{\circ}$, and $90^{\circ}$ (see Figure 1 ).

2.3. Split-Hopkinson Pressure Bar (SHPB). The SHPB system was composed of a gas gun, a striker, an incident bar, a transmission bar, and a data acquisition system (see Figure 2). The incident and transmission bars were made of high-strength steel and had diameters of $50 \mathrm{~mm}$. The sample was clamped between the incident bar and the transmission bar, and the high-pressure nitrogen gas drove the striker in the gas gun, impacting the incident bar and generating a compressive stress wave $\sigma_{i}(t)$ and reflective tensile stress wave $\sigma_{r}(t)$ in the incident bar and a transmission compressive stress wave $\sigma_{t}(t)$ in the transmitted bar. One strain

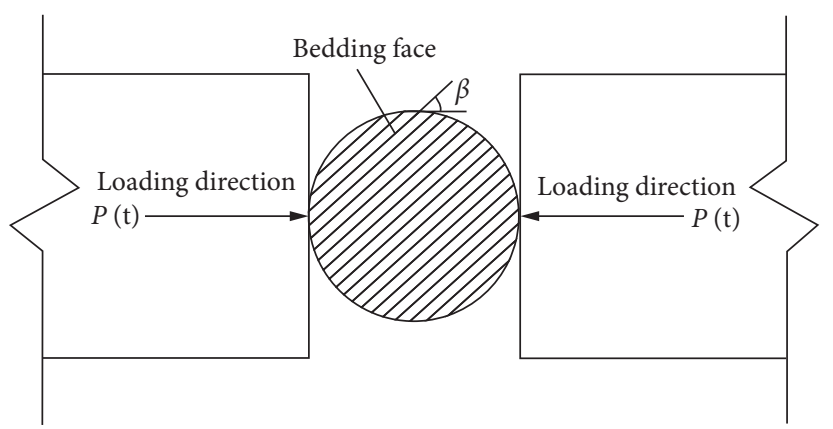

FIgURE 1: Loading method of layered slate for Brazilian splitting testing.

gauge was cemented on the incident bar $1000 \mathrm{~mm}$ from the impact end of the bar to measure the incident and reflected waves (i.e., $\varepsilon_{i}$ and $\varepsilon_{r}$ ); and another strain gauge was cemented on the transmission bar $1000 \mathrm{~mm}$ from the sample to measure the transmitted wave (i.e., $\varepsilon_{t}$ ). Assuming one-dimensional stress wave propagation, the forces on both ends of the sample are [32]

$$
\left.\begin{array}{l}
P_{1}=A E\left(\varepsilon_{i}+\varepsilon_{r}\right) \\
P_{2}=A E \varepsilon_{t},
\end{array}\right\}
$$

where $P_{1}$ is the force on the incident end of the specimen; $P_{2}$ is the force on the transmitted end of the specimen; $E$ is Young's modulus of the bar material; $A$ is the cross-sectional area; $\varepsilon_{i}$ and $\varepsilon_{r}$ are the incident strain signal and reflected strain signal, respectively; and $\varepsilon_{t}$ is the transmitted strain signal.

2.4. BD Method. Rock tensile strength is generally measured by direct tensile tests and indirect tensile tests. The direct tensile test of rock is difficult to conduct, whereas the disc specimen of an indirect tensile test allows a much easier testing process, and theoretical analysis under static and dynamic loading is very mature and widely used. The indirect tensile test was based on the linear elastic solution of the problem of compression along the diameter of a cylindrical disc. At the centre of the disc, this solution is [22]

$$
\left\{\begin{array}{c}
\sigma_{t}=\frac{2 P_{f}}{\pi D t} \\
\sigma_{c}=\frac{6 P_{f}}{\pi D t}
\end{array}\right.
$$

where $\sigma_{t}$ and $\sigma_{c}$ are the tensile and compressive stress of the centre point of the disc and $P_{f}$ is the force acting on the sample with thickness $t$ and diameter $D$.

2.5. Load Rate Effect. The dynamic loading of a test is usually characterized by the strain rate but can also be characterized using the loading rate. The loading rate is the slope of the stress-strain curve before the failure point (see in Figure 3). The loading history was calculated using equation (3) for compressive stress [21]: 


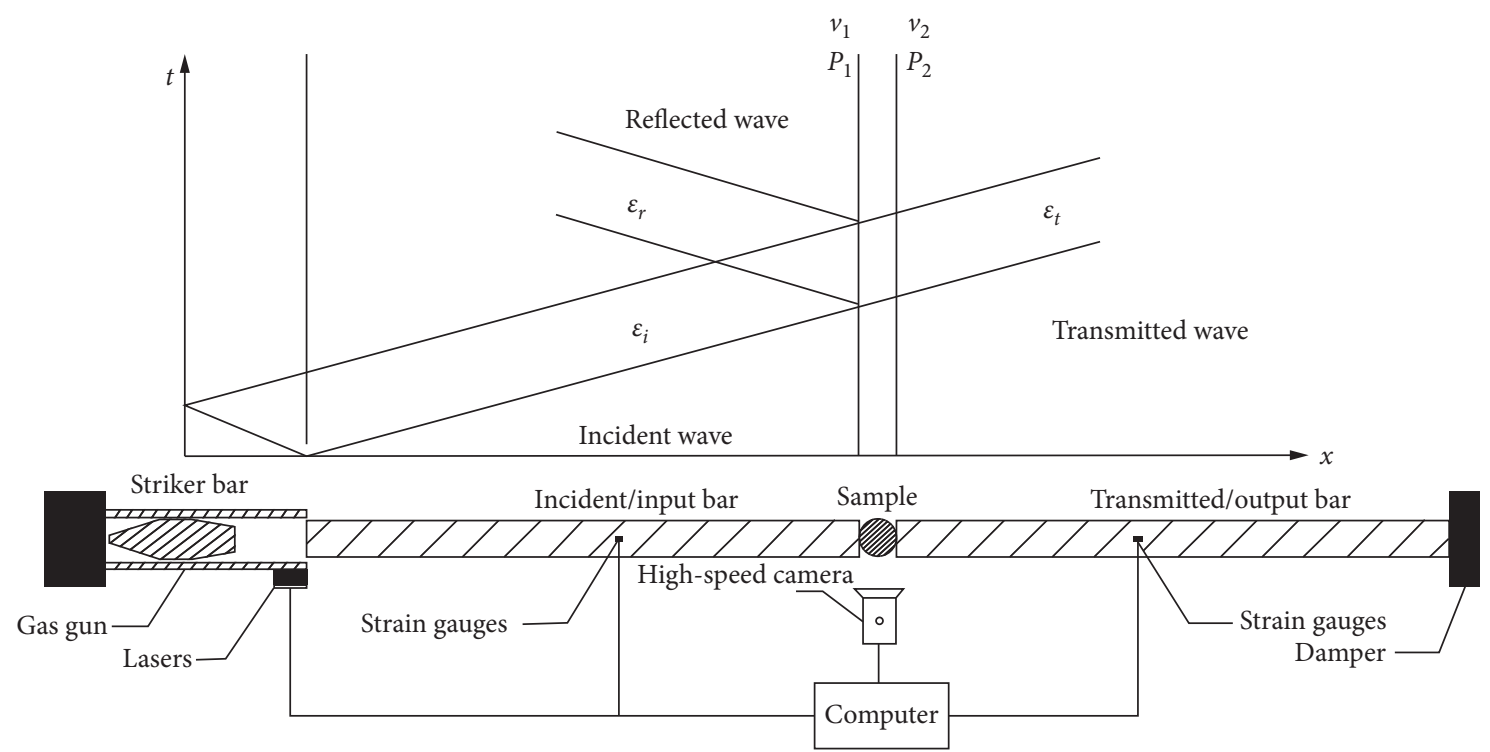

FIGURE 2: Schematics of a split-Hopkinson pressure bar (SHPB) system and the x-t diagram of stress wave propagation in the SHPB.

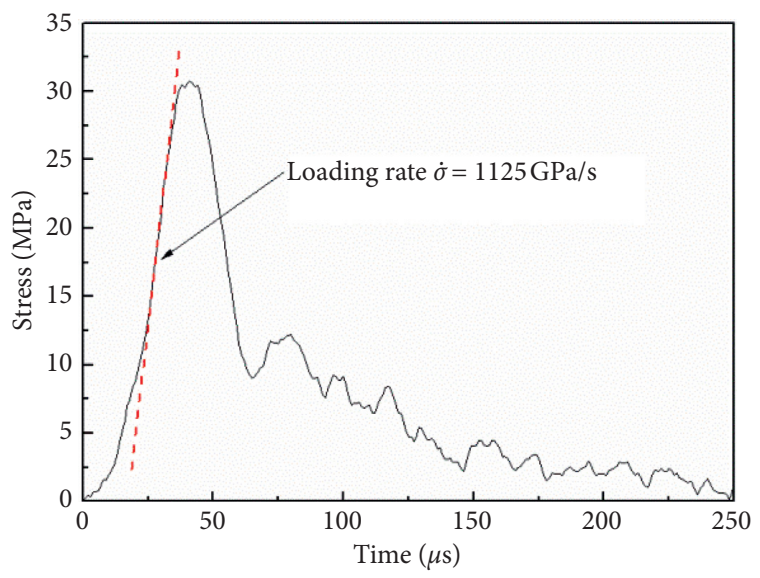

FIGURE 3: The loading rate for the dynamic tensile test.

$$
\sigma(t)=\frac{A E}{2 A_{s}}\left[\varepsilon_{i}(t)+\varepsilon_{r}(t)+\varepsilon_{t}(t)\right]
$$

where $\sigma(t)$ is the axial compressive stress of the sample at time $t, A$ is the cross-sectional area of the bar, $E$ is Young's modulus of the elastic bars, $A_{s}$ is the cross-sectional area of the specimen, $\varepsilon(t)$ denotes the strain at time $t$, and the subscripts $i, r$, and $t$ refer to the incident, reflected, and transmitted waves, respectively.

\section{Testing Results and Discussion}

3.1. Dynamic Force Balance. The prerequisite of the SHPB technique for rock testing under tension is stress equilibrium in the sample. The recorded strain signals from the incident/transmission bars when the loading rate is $\dot{\sigma}=$ $535 \mathrm{GPa} / \mathrm{s}$ and inclination angle of bedding is $\beta=90^{\circ}$ are shown in Figure 4(a). The loading rate computed by using equation (3) is shown in Figure 3. This result can also be drawn from the three-wave equilibrium, as shown in
Figure 4(b), because the force is superimposed (In.+ Re.) on the incident end and is balanced with the force at the transmitted end.

3.2. Effect of Loading Rate. The loading rate is one of the most important indicators of rock dynamics, whereas the change in loading rate greatly affects the dynamic characteristics of the rock. Figure 5 shows the entire process curve of compressive stress and strain in the centre point of the disc under the same inclination angle for three different types of loading. The first type of loading is with the loading rate between $200 \mathrm{GPa} / \mathrm{s}$ and $400 \mathrm{GPa} / \mathrm{s}$. The second type is with the loading rate between $400 \mathrm{GPa} / \mathrm{s}$ and $600 \mathrm{GPa} / \mathrm{s}$. The third type of rock sample loading rate is above $600 \mathrm{GPa} / \mathrm{s}$. Figures $5(\mathrm{a})-5(\mathrm{~g})$ indicate that the inclination angles are $0^{\circ}$, $15^{\circ}, 30^{\circ}, 45^{\circ}, 60^{\circ}, 75^{\circ}$, and $90^{\circ}$, respectively. Figure $5(\mathrm{~h})$ shows the method for solving the dynamic elastic modulus $E$ and postpeak stress reduction rate $\mathrm{K}$ under the SHPB test.

Figures 5(a)-5(g) show that, before the peak stress, the stress-strain curves of all the discs showed a linear rise, corresponding to typical characteristics of the elastic phase (see Figure 5(h)). At this time, the stress and strain follow Hooke's law, and the relationship is as follows:

$$
\sigma_{c}=E \varepsilon_{c}
$$

where $\sigma_{c}$ is the compressive stress of the centre point of the disc, $E$ is the elastic modulus, and $\varepsilon_{c}$ is the compressive strain of the centre point of the disc.

When the stress ranged from $2 / 3$ of the peak stress to the peak stress, the stress-strain curve gradually deviated from the straight line, and the slope slightly decreased (see Figure 5(h), yield stage). As the loading rate increased, the peak stress of the rock was greater (see Figures 5(a)-5(g)). After the peak stress, the strength of the rock mass did not show characteristics of a brittle material and rapidly decreased to zero, but with some remaining residual strength. 

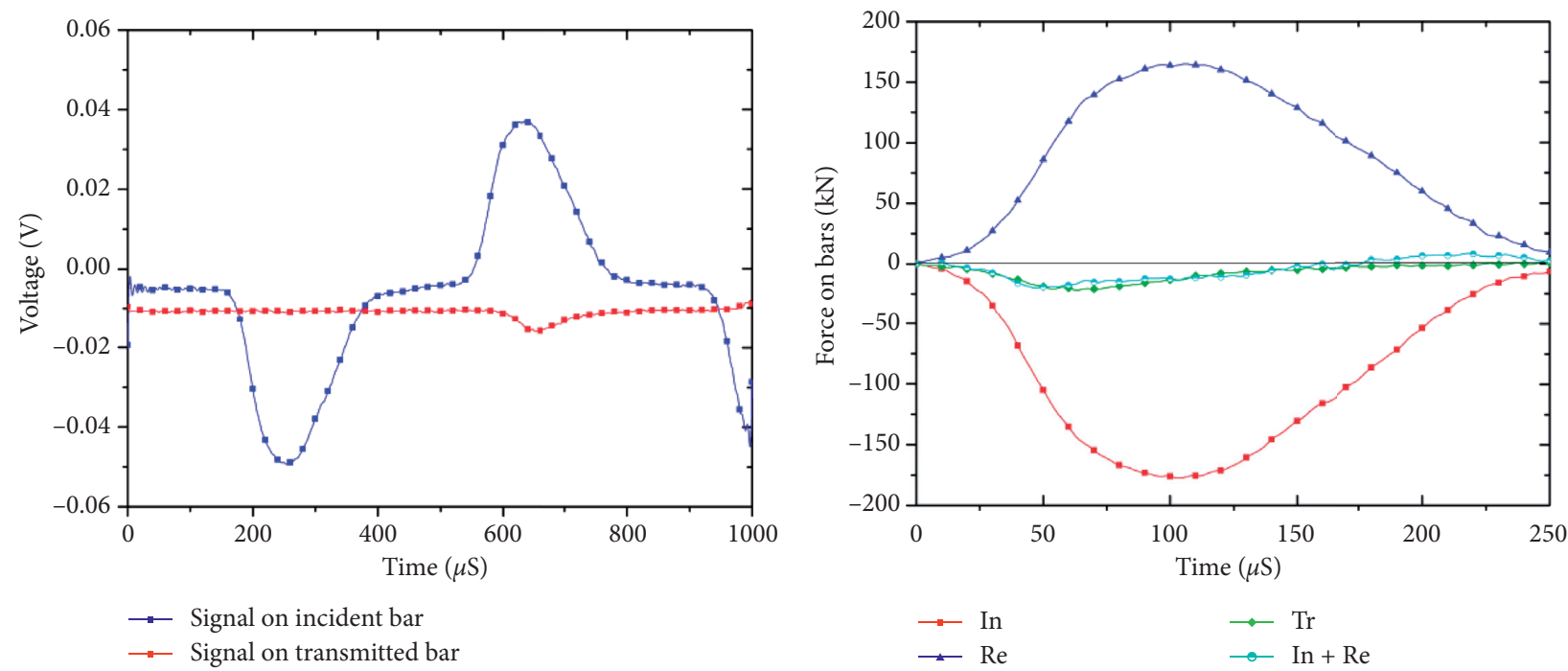

(a)

(b)

Figure 4: Experiential results of the dynamic Brazilian disc test at $\dot{\sigma}=535 \mathrm{GPa} / \mathrm{s}$ and $\beta=90^{\circ}$. (a) Raw data recorded from the gauges mounted on the bars and the specimen. (b) The incident (In.), reflected (Re.), transmitted (Tr.), and superposed (In. + Re.) waves after the time shift by the three-wave method.
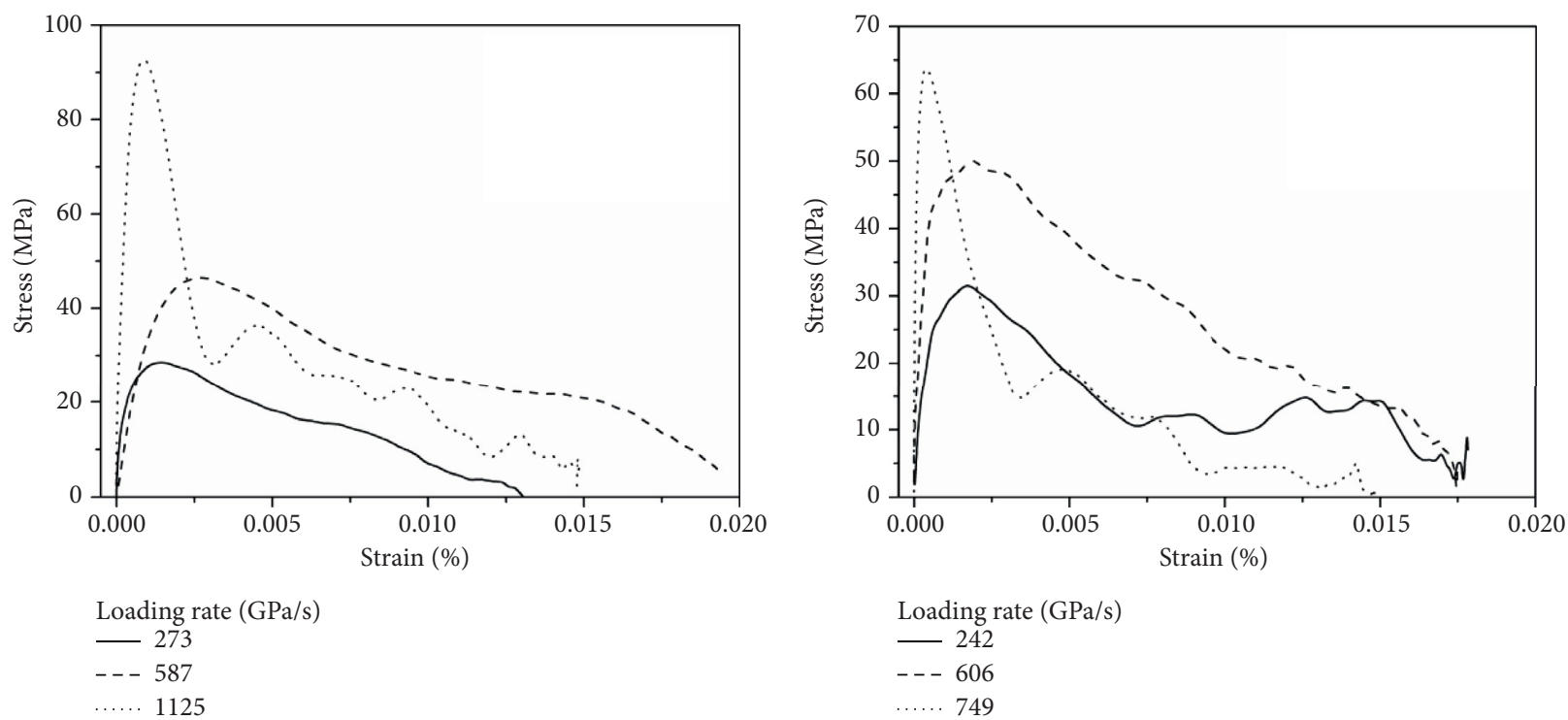

(a)

(b)

FIGURE 5: Continued. 

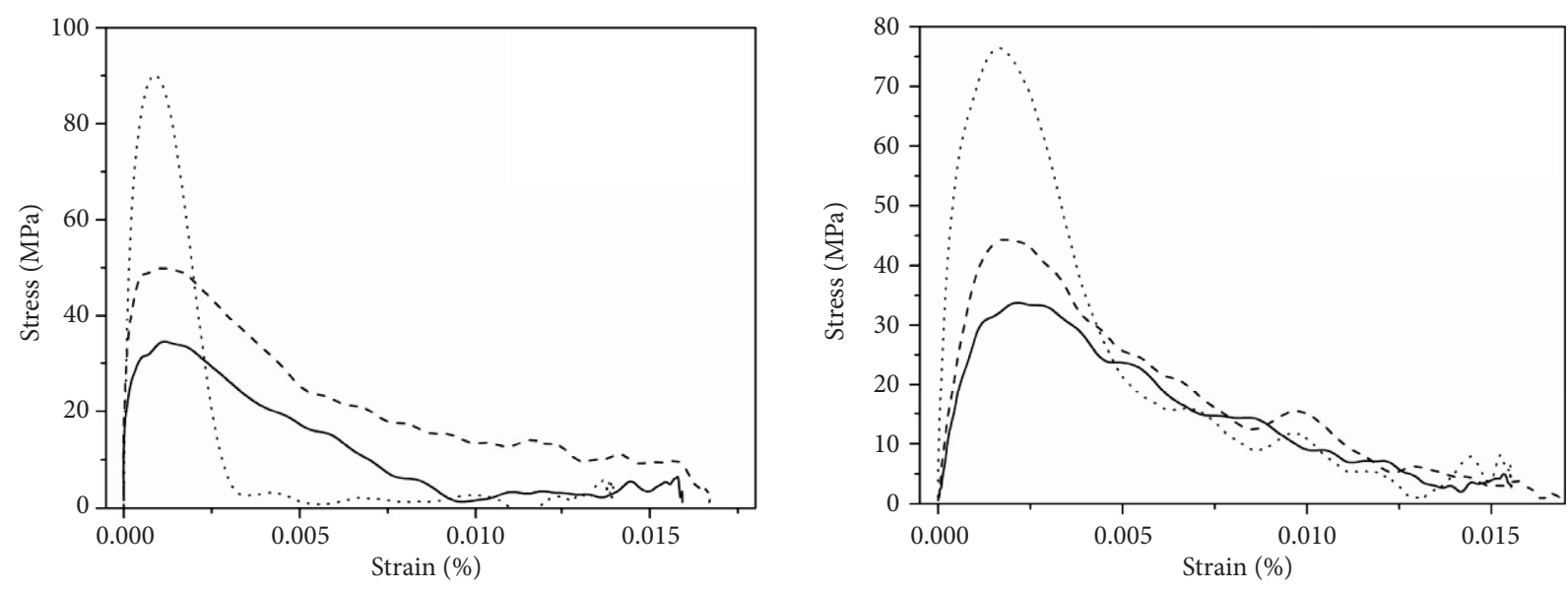

Loading rate (GPa/s)

Loading rate $(\mathrm{GPa} / \mathrm{s})$

- 224

- 291

-- 503

$-511$

…. 799

(c)
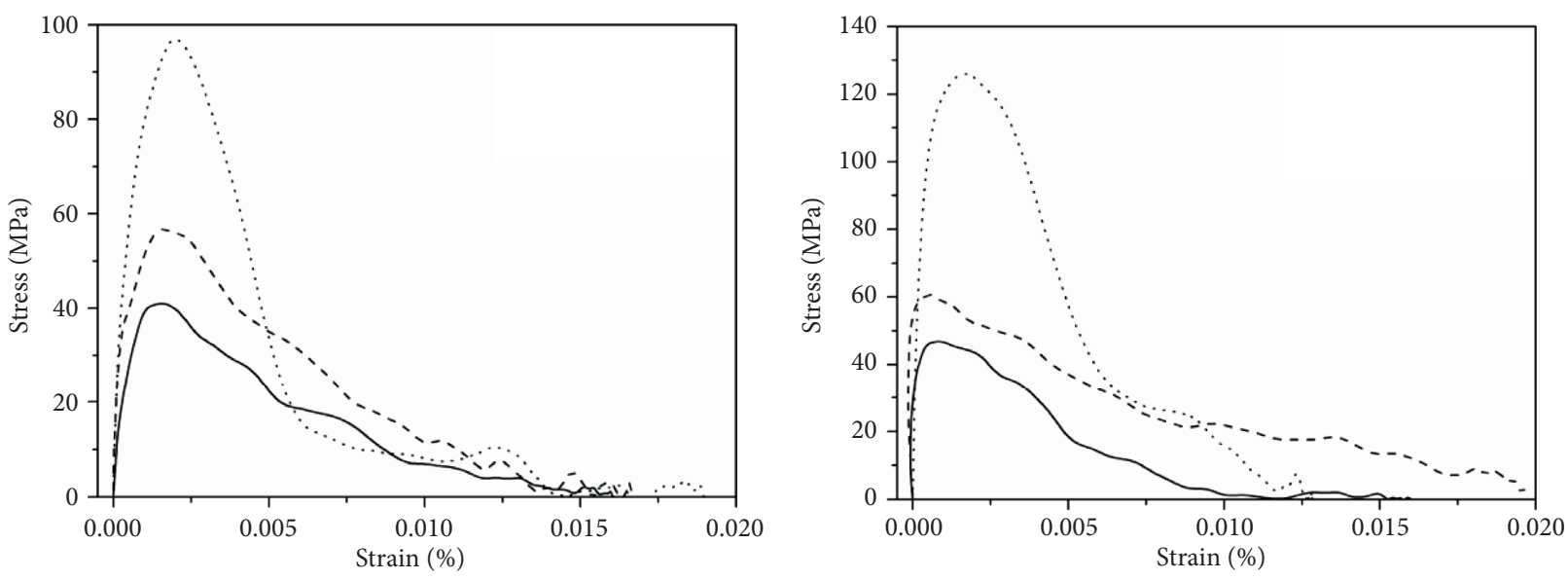

Loading rate $(\mathrm{GPa} / \mathrm{s})$

$-375$

Loading rate $(\mathrm{GPa} / \mathrm{s})$

- - 561

- 408

- - 599

..... 1126

(e)

(f)

Figure 5: Continued. 


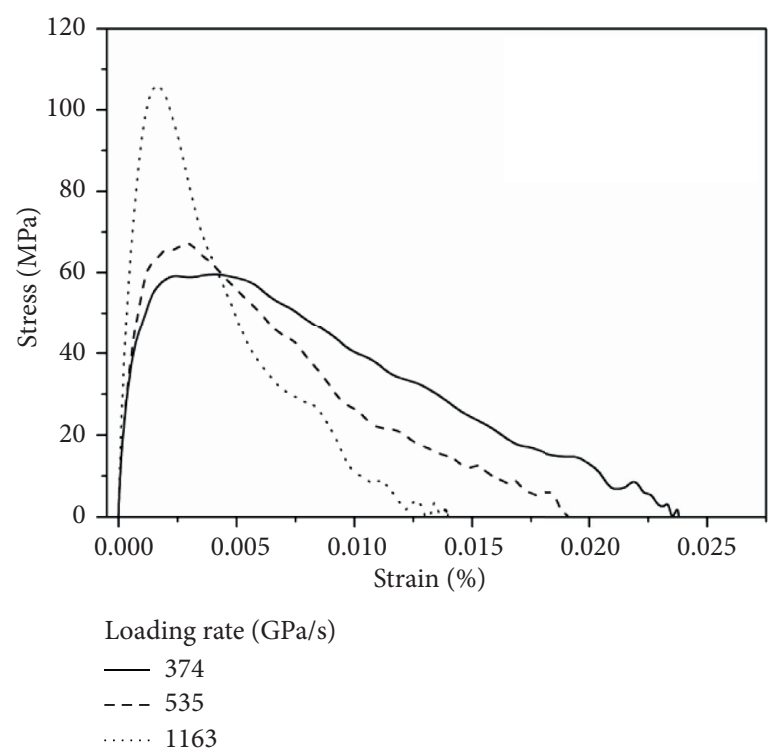

(g)

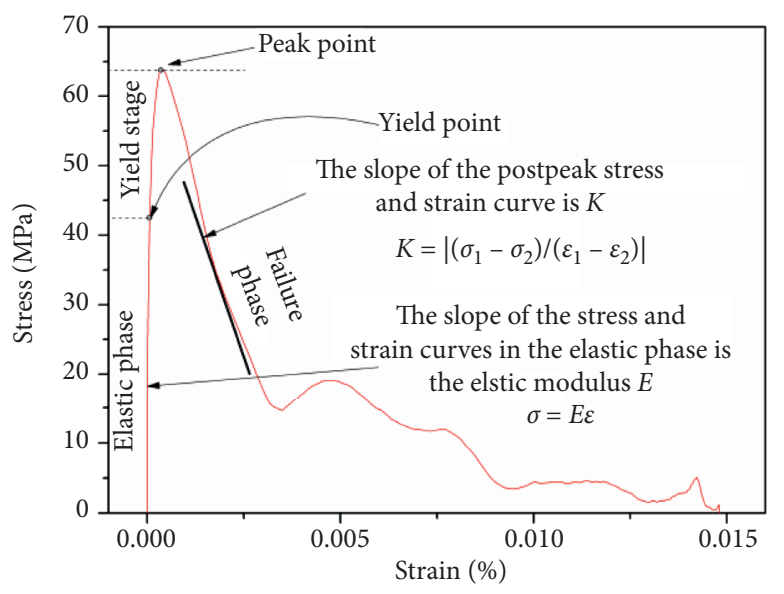

(h)

Figure 5: Stress and strain under three different types of loading rates: 200 to $400 \mathrm{GPa} / \mathrm{s}, 400$ to $600 \mathrm{GPa} / \mathrm{s}$, and above $600 \mathrm{GPa} / \mathrm{s}$. (a-g) The inclination angles of $0^{\circ}, 15^{\circ}, 30^{\circ}, 45^{\circ}, 60^{\circ}, 75^{\circ}$, and $90^{\circ}$, respectively; h is the schematic diagram of $E$ and $K$.

With increasing loading rate, the postpeak stress decreased faster. These results indicate that the rock structure still possessed a certain carrying capacity even after being destroyed at a high loading rate. To study the relationship between the loading rate and the postpeak intensity decline rate, a postpeak stress reduction rate $K$ is introduced here (see Figure 5(h), failure phase), and its expression is as follows:

$$
K=\left|\frac{\sigma_{1}-\sigma_{2}}{\varepsilon_{1}-\varepsilon_{2}}\right|,
$$

where $K$ is the postpeak stress reduction rate, $\mathrm{GPa}$, and $\sigma_{1}$, $\sigma_{2}, \varepsilon_{1}$, and $\varepsilon_{2}$ are the values of stress and strain at a point on the postpeak stress-strain curve.

Dynamic elastic modulus $E$ and postpeak stress reduction rate $K$ of all samples are recorded in Table 1 and plotted in Figure 6. The results in Figure 6(a) show that the elastic modulus increases with increasing loading rate, and as the inclination angle increases, the elastic modulus increases at the same loading rate. In Figure 6(b), it can be seen that the value of the postpeak stress reduction rate $K$ increases with increasing loading rate. However, the loading rate is lower than $600 \mathrm{GPa} / \mathrm{s}$, and the increase in the $K$ value is not obvious. When the loading rate is lower than $600 \mathrm{GPa} / \mathrm{s}$, the postpeak strength of the rock slowly decreases to 0 . After rock failure, the bearing capacity of the rock does not immediately reduce to zero. However, if the loading rate exceeds $600 \mathrm{GPa} / \mathrm{s}$, the postpeak strength decreases rapidly to 0 , and the bearing capacity reduces to zero rapidly after rock failure. The rock strength increases with increasing loading rate, but the rock loses its bearing capacity once it begins to break, which can be taken into account in practical engineering. This $K$ value decreases with increasing bedding angle at the same loading rate when the loading rate exceeds $600 \mathrm{GPa} / \mathrm{s}$.

The fracture modes of the Brazilian split test for transversely isotropic rocks are divided into three types, such as tensile failure, shear failure, and mixed tensile and shear failure. Although the BD method uses formula (2) to calculate the tensile stress based on the centre of the disc crack, there is still a large compressive stress in the centre of the disc between both loading lines. Formula (2) will be further used but only for comparison purposes [10]. The strength calculated by formula (2) is defined as the "failure load" can more accurately reflect the real situation. According to previous research [33], the dynamic failure load and loading rate can be fitted by the following formula:

$$
\sigma=a+b \dot{\sigma}^{n}
$$

where $\sigma$ is the dynamic failure load, $\dot{\sigma}$ is the loading rate, $a$ is the static failure load, and $b$ and $n$ are the loading rate factor. The static failure load measured by the rock testing machine RMT-150C is shown in Table 2. The dynamic failure load measured by the SHPB testing is shown in Table 3.

Figures $7(\mathrm{a})-7(\mathrm{~g})$ show the relationship between the dynamic failure load and the loading rate when the inclination angles of the rock sample were $0^{\circ}, 15^{\circ}, 30^{\circ}, 45^{\circ}, 60^{\circ}, 75^{\circ}$, and $90^{\circ}$, respectively. It can be seen from Figure 7 that the failure load of the rock increases with increasing loading rate under the 7 tested bedding angles. Influenced by the bedding angle, the failure load significantly varies with the increase in the loading rate under the 7 tested bedding angles. The failure load and loading rate fitting formulas are obtained as follows: 
Table 1: Dynamic elastic modulus $E$ and postpeak stress reduction rate $K$.

\begin{tabular}{|c|c|c|c|c|}
\hline $\begin{array}{l}\text { Specimen } \\
\text { no. }\end{array}$ & $\begin{array}{c}\text { The inclination angles } \beta \\
\left({ }^{\circ}\right)\end{array}$ & $\begin{array}{l}\text { Loading rate (GPa/ } \\
\mathrm{s})\end{array}$ & $\begin{array}{c}\text { Dynamic elastic modulus } E \\
\qquad(\mathrm{GPa})\end{array}$ & Postpeak stress reduction rate $K(\mathrm{GPa})$ \\
\hline A-3 & & 273 & 29.28 & 1.23 \\
\hline A-1 & 0 & 587 & 41.76 & 32.82 \\
\hline A- 10 & & 1125 & 133.26 & 41.76 \\
\hline E-1 & & 242 & 34.53 & 4.23 \\
\hline E-3 & 15 & 606 & 90.36 & 4.29 \\
\hline E-6 & & 749 & 164.19 & 20.79 \\
\hline F-2 & & 224 & 47.43 & 4.74 \\
\hline F-1 & 30 & 511 & 63.36 & 7.17 \\
\hline F-5 & & 1132 & 102.45 & 55.62 \\
\hline B-6 & & 291 & 52.86 & 4.38 \\
\hline B-2 & 45 & 503 & 82.53 & 5.34 \\
\hline B-7 & & 799 & 134.4 & 23.16 \\
\hline C-5 & & 375 & 50.1 & 5.37 \\
\hline C-7 & 60 & 561 & 133.29 & 3.9 \\
\hline C-8 & & 750 & 158.13 & 26.16 \\
\hline$\overline{G-4}$ & & 408 & 93.96 & 8.13 \\
\hline G-2 & 75 & 599 & 154.86 & 5.61 \\
\hline G-6 & & 1398 & 177.78 & 29.52 \\
\hline$\overline{D-1}$ & & 374 & 75.93 & 3.45 \\
\hline D-5 & 90 & 535 & 145.26 & 6.03 \\
\hline D-7 & & 1163 & 184.86 & 15.33 \\
\hline
\end{tabular}

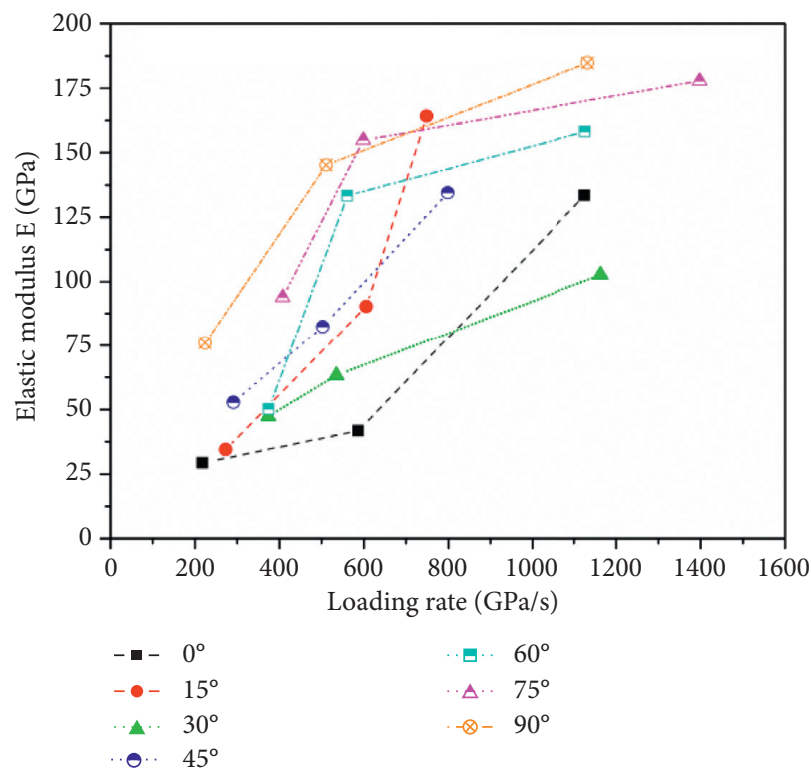

(a)

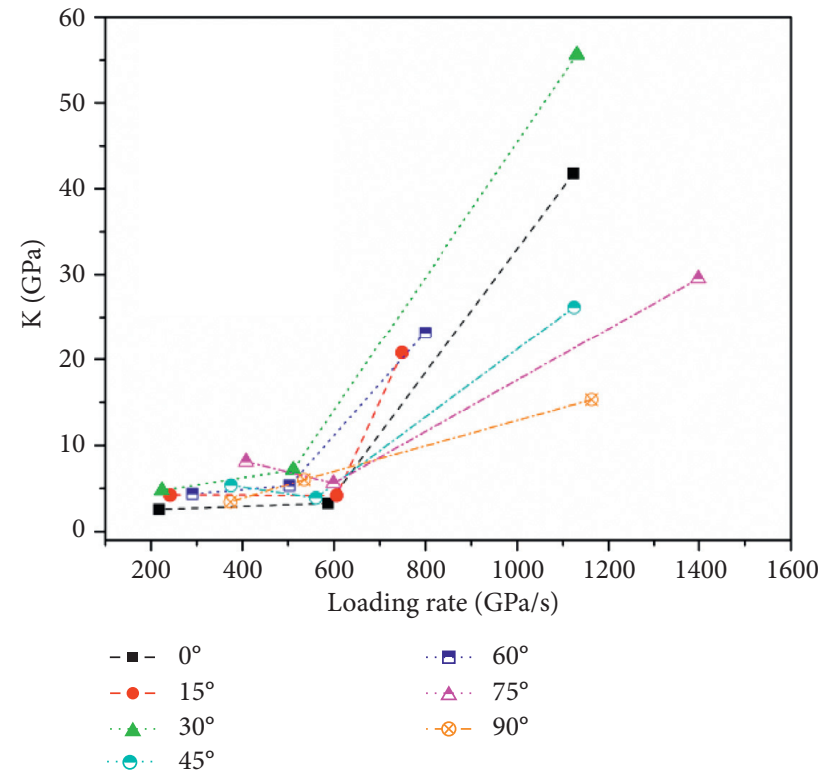

(b)

FIGURE 6: The elastic modulus $\mathrm{E}$ and postpeak stress reduction rate $\mathrm{K}$ after different loading rates. (a) Law of the change in elastic modulus $\mathrm{E}$ with loading rate. (b) Law of the change in $\mathrm{K}$ with loading rate. 
TABLE 2: Summary of the static tensile test results on samples.

\begin{tabular}{|c|c|c|c|c|c|}
\hline Specimen no. & The inclination angles $\beta\left({ }^{\circ}\right)$ & Diameter $(\mathrm{mm})$ & Thickness (mm) & Static failure load (MPa) & Average failure load $(\mathrm{MPa})$ \\
\hline SA-1 & \multirow{3}{*}{0} & 49.58 & 23.77 & 2.36 & \multirow{3}{*}{2.75} \\
\hline SA-2 & & 48.65 & 25.56 & 3.53 & \\
\hline SA-3 & & 48.61 & 25.19 & 2.36 & \\
\hline SE-1 & \multirow{3}{*}{15} & 49.56 & 26.70 & 3.85 & \multirow{3}{*}{4.02} \\
\hline SE-2 & & 48.62 & 25.64 & 4.42 & \\
\hline SE-3 & & 48.77 & 25.22 & 3.79 & \\
\hline SF-1 & \multirow{3}{*}{30} & 49.56 & 23.72 & 2.63 & \multirow{3}{*}{3.87} \\
\hline SF-2 & & 48.67 & 26.07 & 4.51 & \\
\hline SF-3 & & 48.65 & 25.89 & 4.48 & \\
\hline SB-1 & \multirow{3}{*}{45} & 49.46 & 25.69 & 5.49 & \multirow{3}{*}{5.12} \\
\hline SB-2 & & 48.70 & 24.03 & 4.56 & \\
\hline SB-3 & & 48.61 & 25.45 & 5.32 & \\
\hline SC-1 & \multirow{4}{*}{60} & 49.55 & 26.16 & 3.71 & \multirow{4}{*}{4.13} \\
\hline SC-2 & & 48.63 & 25.49 & 5.22 & \\
\hline SC-3 & & 48.64 & 25.80 & 4.45 & \\
\hline SC-4 & & 48.72 & 26.23 & 3.15 & \\
\hline SG-1 & \multirow{3}{*}{75} & 49.74 & 27.66 & 7.94 & \multirow{3}{*}{8.14} \\
\hline SG-2 & & 48.7 & 25.86 & 9.04 & \\
\hline SG-3 & & 48.61 & 25.97 & 7.45 & \\
\hline SD-1 & \multirow{3}{*}{90} & 49.59 & 26.90 & 8.44 & \multirow{3}{*}{8.92} \\
\hline SD-2 & & 48.61 & 25.33 & 9.13 & \\
\hline SD-3 & & 48.68 & 25.50 & 9.20 & \\
\hline
\end{tabular}

TABle 3: Summary of the dynamic tensile test results on samples.

\begin{tabular}{|c|c|c|c|c|c|}
\hline Sample number & Inclination angles $\left({ }^{\circ}\right)$ & Diameter $(\mathrm{mm})$ & Thickness $(\mathrm{mm})$ & Loading rate $(\mathrm{GPa} / \mathrm{s})$ & Dynamic failure load (MPa) \\
\hline $\bar{A}-1$ & \multirow{7}{*}{0} & 49.49 & 24.60 & 587 & 15.50 \\
\hline A-2 & & 49.09 & 23.81 & 406 & 15.68 \\
\hline A-3 & & 49.37 & 26.77 & 273 & 11.50 \\
\hline A-4 & & 49.61 & 24.30 & 488 & 14.81 \\
\hline A-5 & & 49.63 & 24.84 & 218 & 10.11 \\
\hline A- 6 & & 49.51 & 24.16 & 519 & 15.53 \\
\hline A-7 & & 49.42 & 24.53 & 1126 & 31.16 \\
\hline$\overline{E-1}$ & \multirow{6}{*}{15} & 48.65 & 24.96 & 242 & 10.79 \\
\hline E-2 & & 48.75 & 25.70 & 419 & 16.57 \\
\hline E-3 & & 48.68 & 25.91 & 606 & 17.05 \\
\hline E-4 & & 48.65 & 26.12 & 290 & 11.95 \\
\hline E-5 & & 48.43 & 25.45 & 475 & 15.45 \\
\hline E-6 & & 48.66 & 26.13 & 749 & 21.71 \\
\hline$\overline{F-1}$ & \multirow{5}{*}{30} & 48.51 & 25.58 & 511 & 17.01 \\
\hline F-2 & & 48.79 & 25.17 & 224 & 12.07 \\
\hline F-3 & & 48.69 & 25.60 & 238 & 12.00 \\
\hline F-4 & & 48.66 & 25.76 & 222 & 10.40 \\
\hline F-5 & & 48.79 & 25.12 & 1132 & 30.27 \\
\hline B-1 & \multirow{6}{*}{45} & 49.69 & 26.71 & 411 & 15.11 \\
\hline B-2 & & 49.58 & 27.47 & 503 & 15.06 \\
\hline B-4 & & 49.54 & 27.05 & 500 & 13.82 \\
\hline B-5 & & 49.54 & 24.06 & 521 & 16.78 \\
\hline B-6 & & 49.55 & 27.35 & 291 & 12.31 \\
\hline B-9 & & 49.52 & 24.48 & 799 & 26.23 \\
\hline C-1 & \multirow{6}{*}{60} & 48.65 & 25.42 & 386 & 11.93 \\
\hline C-4 & & 48.66 & 25.72 & 532 & 15.26 \\
\hline C-5 & & 48.69 & 26.24 & 375 & 13.75 \\
\hline C-6 & & 48.68 & 25.70 & 544 & 19.48 \\
\hline C-7 & & 48.75 & 25.96 & 561 & 18.98 \\
\hline C-8 & & 48.62 & 25.92 & 1126 & 32.8 \\
\hline
\end{tabular}


TABle 3: Continued.

\begin{tabular}{|c|c|c|c|c|c|}
\hline Sample number & Inclination angles $\left({ }^{\circ}\right)$ & Diameter $(\mathrm{mm})$ & Thickness (mm) & Loading rate $(\mathrm{GPa} / \mathrm{s})$ & Dynamic failure load $(\mathrm{MPa})$ \\
\hline G-1 & & 48.64 & 25.15 & 642 & 28.83 \\
\hline G-2 & & 48.61 & 25.68 & 599 & 20.6 \\
\hline G-4 & 75 & 48.70 & 26.25 & 408 & 15.94 \\
\hline G-5 & & 48.72 & 24.89 & 600 & 30.85 \\
\hline G-8 & & 48.68 & 25.76 & 1398 & 42.52 \\
\hline D-1 & & 49.56 & 27.15 & 374 & 19.96 \\
\hline $\mathrm{D}-2$ & & 49.61 & 27.08 & 601 & 21.21 \\
\hline D-3 & & 49.58 & 27.27 & 353 & 20.39 \\
\hline D-4 & 90 & 49.58 & 23.92 & 556 & 19.39 \\
\hline D-5 & & 49.62 & 24.06 & 535 & 23.01 \\
\hline D-6 & & 49.67 & 24.03 & 498 & 20.64 \\
\hline D-7 & & 49.68 & 23.92 & 1163 & 35.78 \\
\hline
\end{tabular}

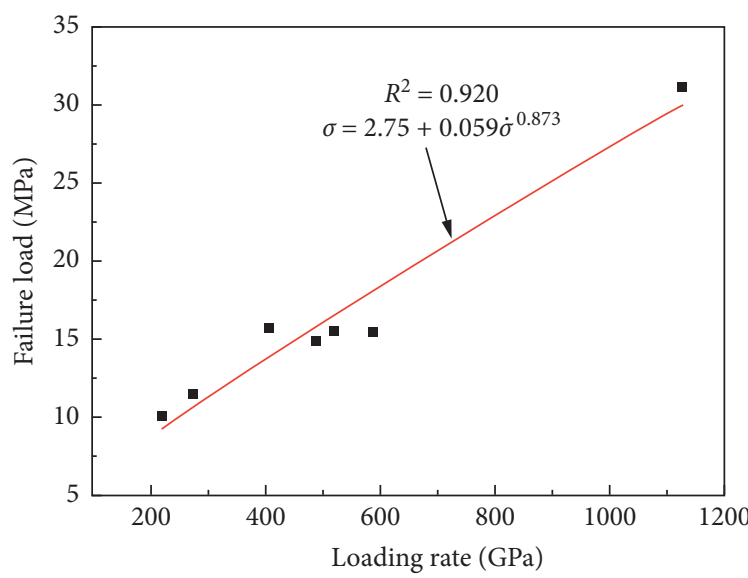

(a)

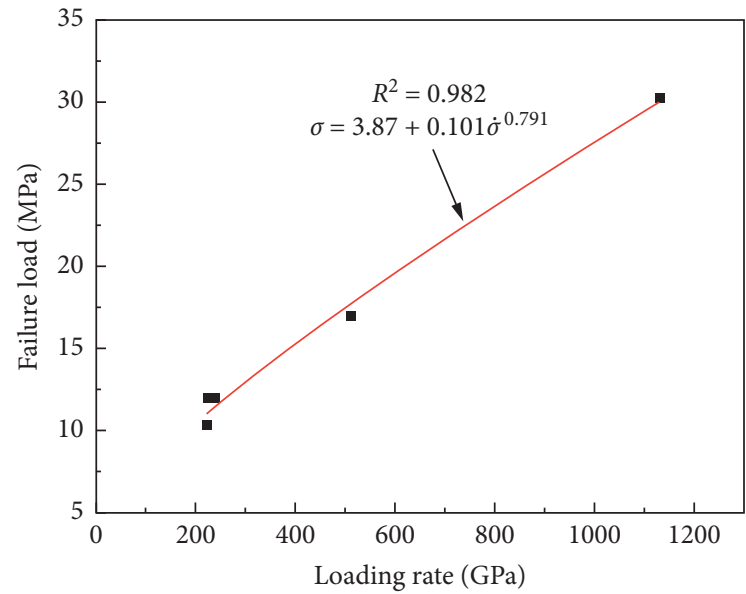

(c)

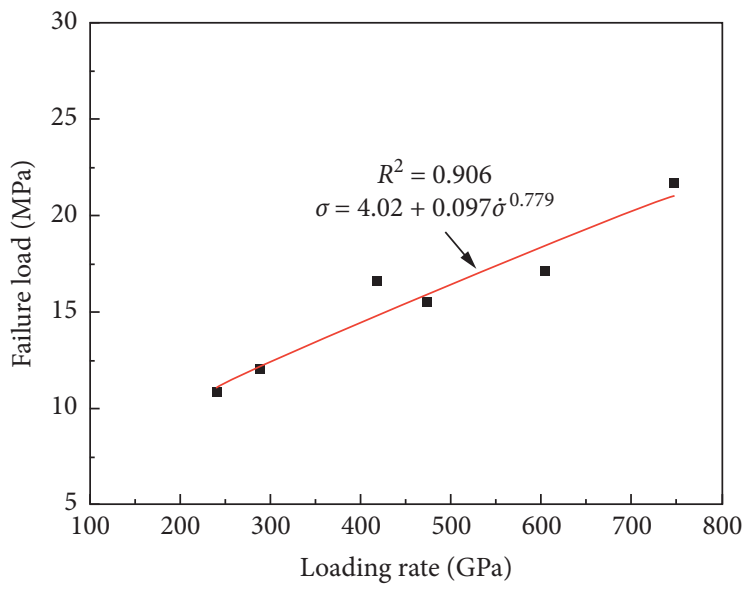

(b)

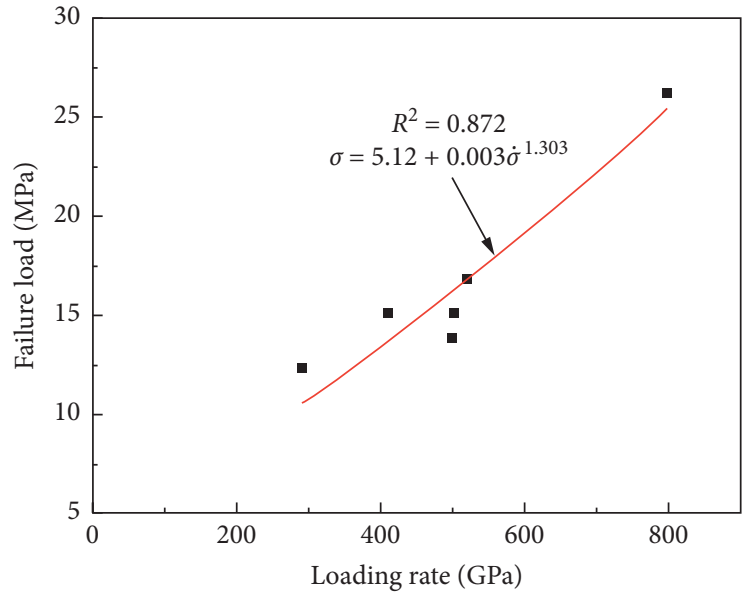

(d)

Figure 7: Continued. 


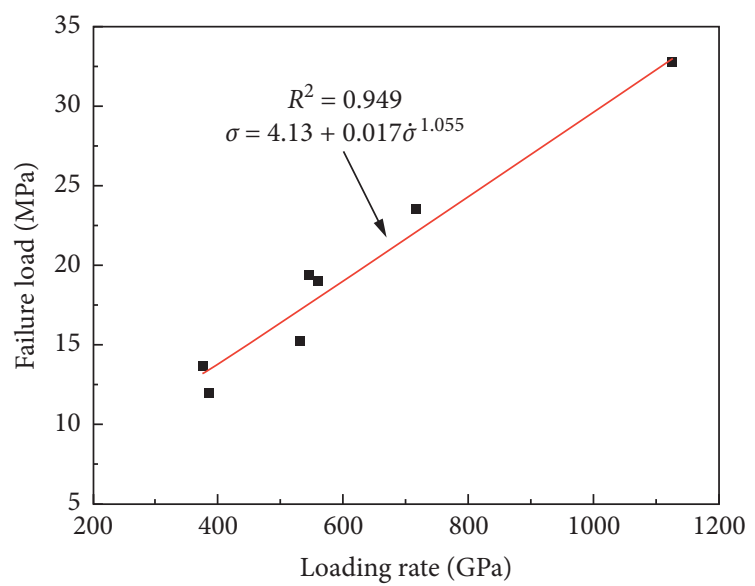

(e)

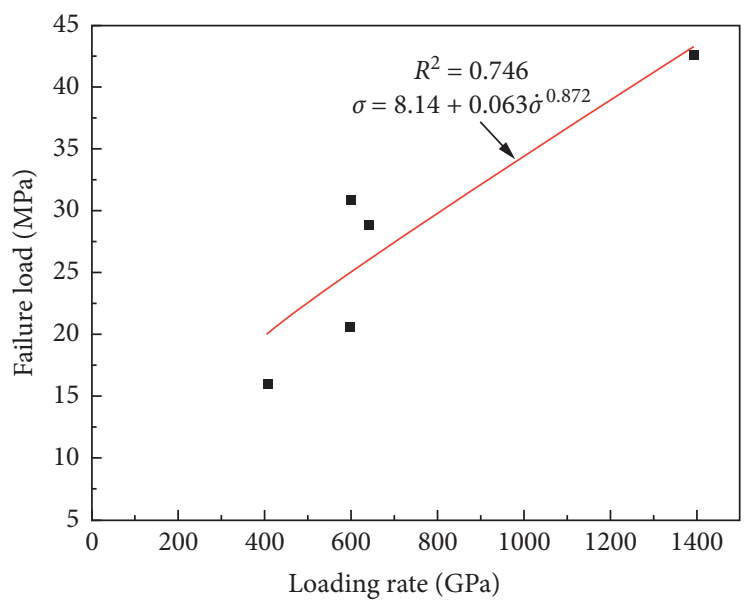

(f)

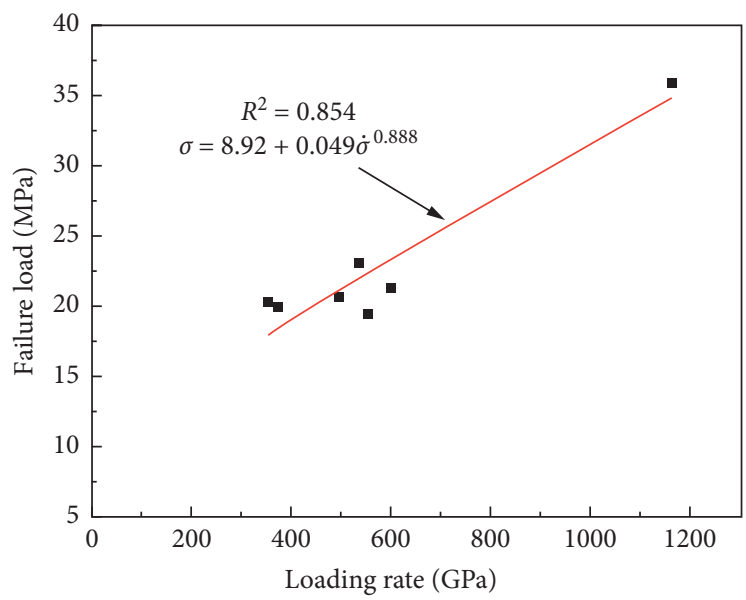

(g)

Figure 7: The relationship between the dynamic failure load and the loading rate. (a-g) The inclination angles of $0^{\circ}, 15^{\circ}, 30^{\circ}, 45^{\circ}, 60^{\circ}, 75^{\circ}$, and $90^{\circ}$, respectively.

$$
\left\{\begin{array}{lll}
\sigma=2.75+0.059 \dot{\sigma}^{0.873}, & \text { Adj. } R^{2}=0.920, & \left(\beta=0^{\circ}\right), \\
\sigma=4.02+0.097 \dot{\sigma}^{0.779}, & \text { Adj. } R^{2}=0.906, & \left(\beta=15^{\circ}\right), \\
\sigma=3.87+0.101 \dot{\sigma}^{0.791}, & \text { Adj. } R^{2}=0.982, & \left(\beta=30^{\circ}\right), \\
\sigma=5.12+0.003 \dot{\sigma}^{1.303}, & \text { Adj. } R^{2}=0.872, & \left(\beta=45^{\circ}\right), \\
\sigma=4.13+0.017 \dot{\sigma}^{1.055}, & \text { Adj. } R^{2}=0.949, & \left(\beta=60^{\circ}\right), \\
\sigma=8.14+0.063 \dot{\sigma}^{0.872}, & \text { Adj. } R^{2}=0.746, & \left(\beta=75^{\circ}\right), \\
\sigma=8.92+0.049 \dot{\sigma}^{0.888}, & \text { Adj. } R^{2}=0.854, & \left(\beta=90^{\circ}\right) .
\end{array}\right.
$$

Figure 8 shows the relationship between the dynamic failure load and loading rate of the 42 samples with different inclination angles. The failure load of the rock mass increased with increasing loading rate under different inclination angles. The influence of the layering on the strength of the rock sample was much smaller than that of the loading rate. The failure load and the loading rate are linearly fitted, with a fitting formula of $\sigma=5.28+0.027 \dot{\sigma}^{0.989}$ (see Figure 8).
3.3. Effect of Bedding Planes. A bedding plane is a discontinuous surface inside rock, and a large difference in mechanical properties occurs perpendicular to the layering and parallel to the layering. Therefore, the inclination angle between the bedding planes and the loading direction affects the internal stress distribution state of the rock mass and the mechanical behaviour of the rock mass. Figure 9 shows the relationship between the stress and strain of the slate during the rock impact test for the two loading rates under different inclination angles. In Figure 9(a), as the bedding inclination angle increases from $0^{\circ}$ and $15^{\circ}$ to $30^{\circ}$, both the dynamic peak stress and the elastic modulus of the rock increase at a loading rate of approximately $240 \mathrm{GPa} / \mathrm{s}$. In Figure 9(b), as the bedding inclination angle increases from $0^{\circ}, 15^{\circ}, 60^{\circ}$, and $75^{\circ}$ to $90^{\circ}$, both the dynamic peak stress and the elastic modulus of the rock increase at a loading rate of approximately $600 \mathrm{GPa} / \mathrm{s}$ (see in Table 4). The stress-strain curves of the rock sample show obvious anisotropy at the same loading rate level, and the stress-strain curve of the rock mass is greatly affected by the inclination angle of the layering. 


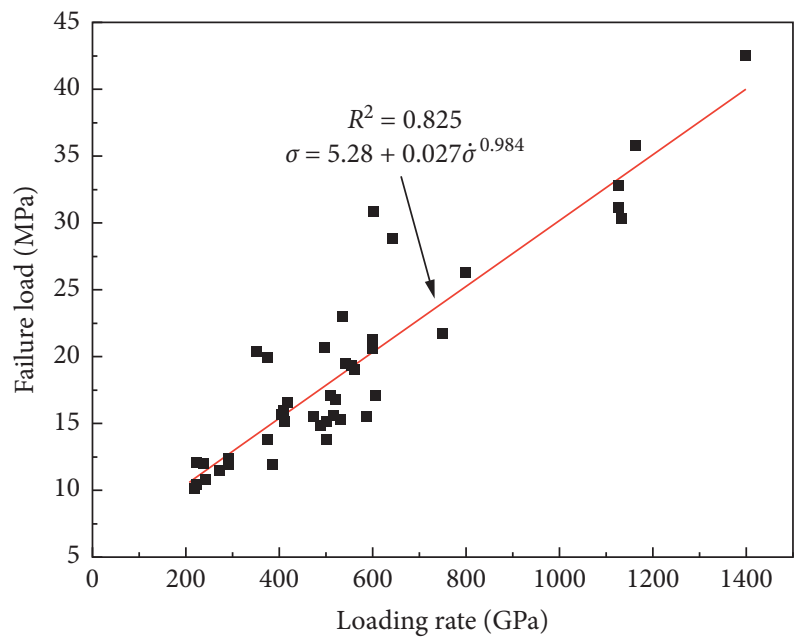

Figure 8: The relationship between the failure load and the loading rate of all the rock samples.

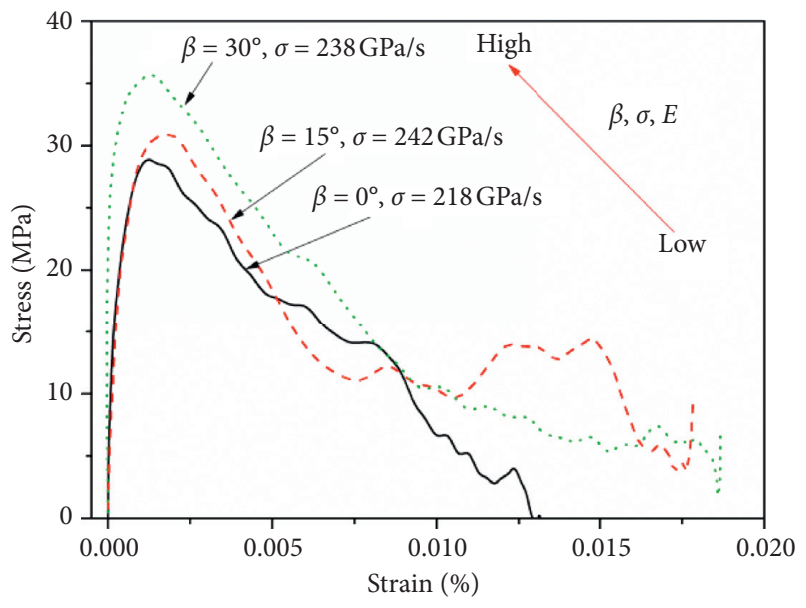

(a)

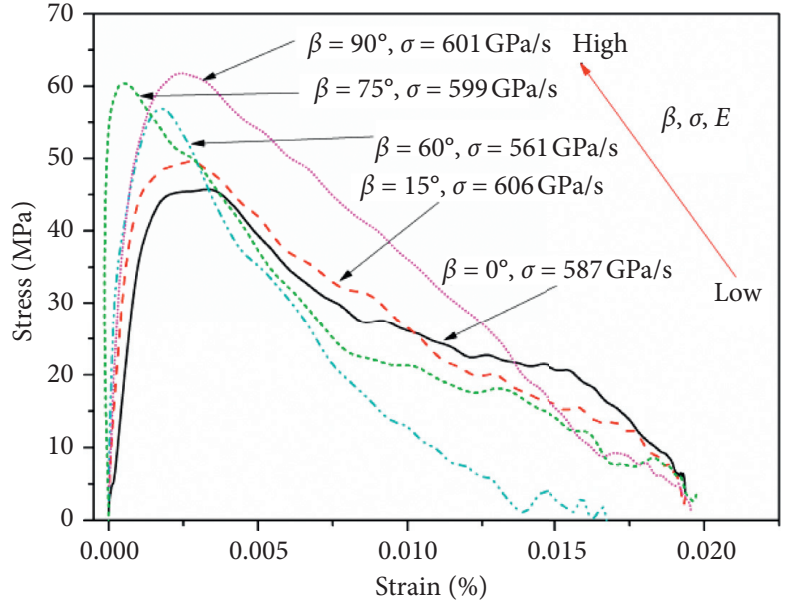

(b)

FIGURE 9: Stress and strain under different inclination angles. (a) The stress-strain curves of $0^{\circ}, 15^{\circ}$, and $30^{\circ}$ at approximately $240 \mathrm{GPa} / \mathrm{s}$. (b) The stress-strain curves of $0^{\circ}, 15^{\circ}, 60^{\circ}, 75^{\circ}$, and $30^{\circ}$ at approximately $600 \mathrm{GPa} / \mathrm{s}$.

TABLE 4: The relationship between bedding inclination angle $\beta$ and tensile strength $\sigma$ and dynamic elastic modulus $E$ (I;is the loading rate about $240 \mathrm{GPa} / \mathrm{s}$; II is the loading rate about $600 \mathrm{GPa} / \mathrm{s}$ ).

\begin{tabular}{|c|c|c|c|c|c|c|}
\hline $\begin{array}{l}\text { Loading rate } \\
\text { type }\end{array}$ & Sample no. & $\begin{array}{c}\text { Inclination angles } \\
\left({ }^{\circ}\right)\end{array}$ & $\begin{array}{l}\text { Loading rate } \\
(\mathrm{GPa} / \mathrm{s})\end{array}$ & $\begin{array}{l}\text { Failure load } \\
(\mathrm{MPa})\end{array}$ & $\begin{array}{c}\text { Dynamic elastic modulus } E \\
(\mathrm{GPa})\end{array}$ & $\begin{array}{c}\text { Indicator } \\
\text { trend }\end{array}$ \\
\hline \multirow{3}{*}{ I } & A-3 & 0 & 273 & 11.50 & 34.56 & \multirow{3}{*}{$\downarrow$} \\
\hline & E-1 & 15 & 242 & 10.79 & 34.53 & \\
\hline & B-6 & 45 & 291 & 12.00 & 52.86 & \\
\hline \multirow{5}{*}{ II } & A-1 & 0 & 587 & 15.55 & 41.76 & \multirow{5}{*}{$\downarrow$} \\
\hline & E-3 & 15 & 606 & 17.05 & 90.36 & \\
\hline & C-7 & 60 & 561 & 18.98 & 133.29 & \\
\hline & G-2 & 75 & 599 & 20.60 & 154.86 & \\
\hline & D-2 & 90 & 601 & 21.21 & 136.86 & \\
\hline
\end{tabular}

Figure 10 shows that the distribution of the average failure load of slate in each inclination angle is affected by the different layer inclination angles under the static load splitting test. As the inclination angle increased from $0^{\circ}$ to $90^{\circ}$, the failure load increased as well. When the inclination angle was $0^{\circ}$, the average value of the failure load was minimized; when the inclination angle was $90^{\circ}$, the average value of the failure load appeared to be the maximum. Here, 


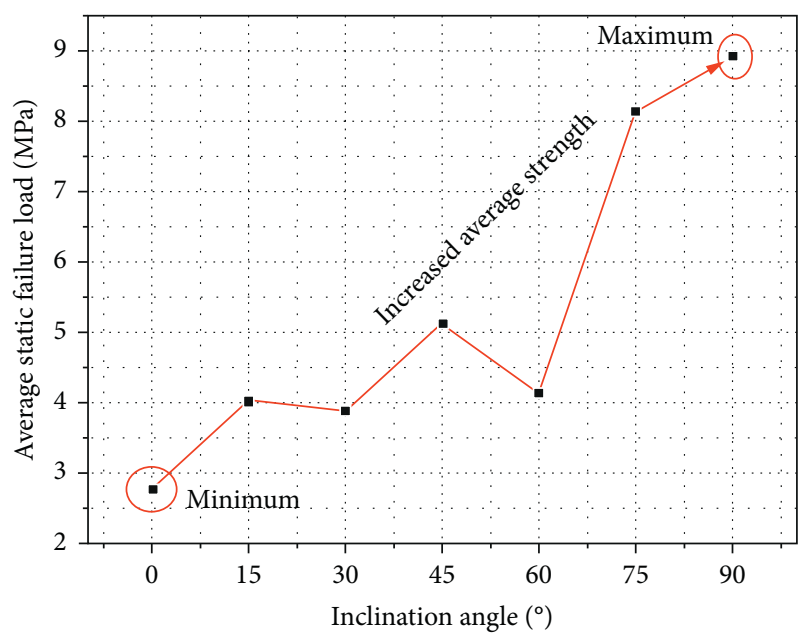

FIgURE 10: The relationship between the average failure load and the inclination angle.

an anisotropic influence coefficient $N$ is introduced, the expression of which is as follows:

$$
N=\frac{\sigma_{\beta=i, \max }}{\sigma_{\beta=j, \min }},
$$

where $N$ is the anisotropic influence coefficient; $i$ and $j$ are the bedding inclination angles; $\sigma_{\beta=i, \max }$ is the maximum of the average values of the failure load at different bedding angles; and $\sigma_{\beta=j \text {,min }}$ is the minimum of the average values of the failure load at different bedding angles. $N$ is 3.24 in the static load splitting tensile test.

Figure 11 shows the relationship between the dynamic failure load and the inclination angle of the layers determined by equation (7) under four loading rates: $200 \mathrm{GPa} / \mathrm{s}$, $600 \mathrm{GPa} / \mathrm{s}, 1000 \mathrm{GPa} / \mathrm{s}$, and $1400 \mathrm{GPa} / \mathrm{s}$. In Figures 11 and 12 , the dynamic failure load is divided into three parts according to the change in inclination angle. The first part is a low-strength area, when the bedding angle is $0^{\circ}$ and tensile failure occurs along the bedding plane; the second part is the middle strength area, when the bedding angle is $15^{\circ}$ to $45^{\circ}$ and shear failure occurs along the bedding plane; the third part is a high-strength area, when the bedding angle is $60^{\circ}$ to $90^{\circ}$ and tensile failure occurs along nonbedding planes. According to the results, the dynamic anisotropic influence coefficients $N$ at different loading rates are 1.79 for $N_{200}, 1.41$ for $N_{600}, 1.36$ for $N_{1000}$, and 1.35 for $N_{1400}$. Therefore, as the loading rate increased, the anisotropic influence coefficient $\mathrm{N}$ decreased and gradually approached 1.35 . In the present case, as the loading rate increased, the bedding effect gradually decreased. When the loading rate was increased to a certain value, the bedding effect became negligible (see Figure 13).

3.4. Failure Mode. This SHPB test used a high-speed camera to monitor the full destruction process over a total of 250 microseconds. In Figure 12, the photos of a, b, c, d, e, f, and g show the splitting damage of the disc under impact load when the inclination angle was $0^{\circ}, 15^{\circ}, 30^{\circ}, 45^{\circ}, 60^{\circ}, 75^{\circ}$, and

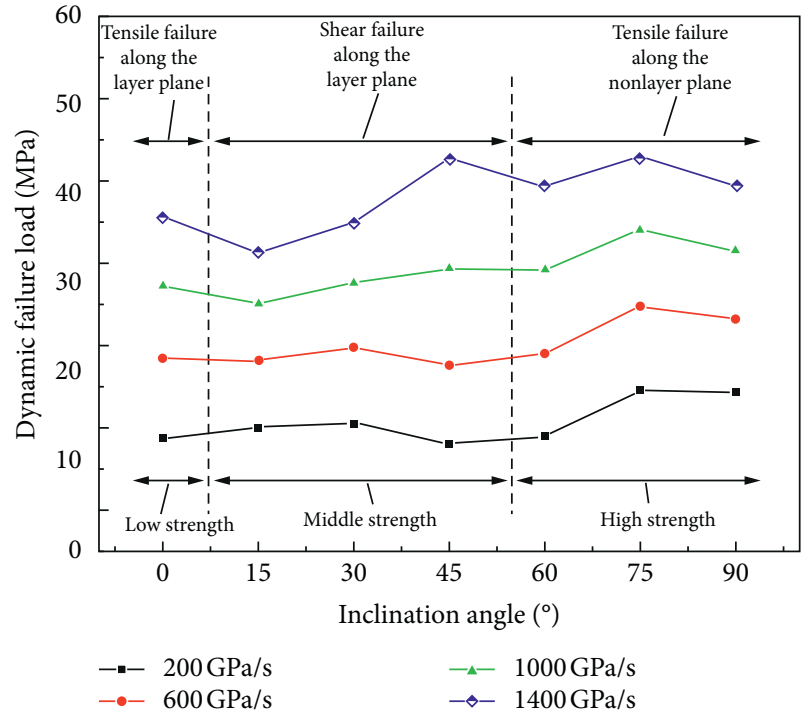

FIgUre 11: The relationship between the dynamic failure load and the inclination angle for four loading rates.

$90^{\circ}$, respectively. The crack in the disc did not extend along the loading direction of the central crack, which was greatly affected by the inclination angle of the bedding plane.

A high-speed camera photographed the fracturing in a disc for 7 inclination angles under loading rates from 400 to $600 \mathrm{GPa} / \mathrm{s}$, and the four resultant failure modes are summarized in Figure 14 according to the photographs of rock failure captured by the high-speed camera.

According to the results from the dynamic Brazilian splitting test, disc fracturing occurred along the central axis and bedding planes when the inclination angle $\beta$ was $0^{\circ}$ (Figure 14(a)). Second, disc fracturing occurred off-centre and along bedding planes when the inclination angle $\beta$ was $15^{\circ}$ (Figure 14(c)). While the inclination angle $\beta$ was $75^{\circ}$, disc fracturing occurred off-centre and along previously intact planes (Figure 14(d)). For other inclination angles, two different fracture types occurred in the same experiment. Disc fracturing occurred off-centre and along bedding and previously intact planes when the inclination angle $\beta$ was $30^{\circ}$ and $45^{\circ}$ (Figure 14(c) and 14(d)). When the inclination angle $\beta$ was $60^{\circ}$ or $90^{\circ}$, disc fracturing occurred along the central axis and off-centre and along previously intact planes (Figures 14(b) and 14(d)). The fracturing of the disc shown in Figure 12 is plotted in Figure 15.

Combined with the dynamic failure load (Figure 11) and the different fracture modes (Figure 14), the main conclusions are as follows: (1) The fracture mode of the disc was mainly tensile failure along the bedding plane when the inclination angle $\beta$ was $0^{\circ}$. Because the tensile strength of the bedding plane is the lowest, the lowest dynamic tensile strength of slate was determined for all of the inclination angles. (2) The fracture mode of the disc was mainly shear failure along the bedding plane when the inclination angle $\beta$ was $15^{\circ}, 30^{\circ}$, and $45^{\circ}$. The dynamic failure load was slightly higher than the dynamic tensile strength when the inclination angle $\beta$ was $0^{\circ}$. This result demonstrates that the shear strength of the bedding plane was higher than its tensile 


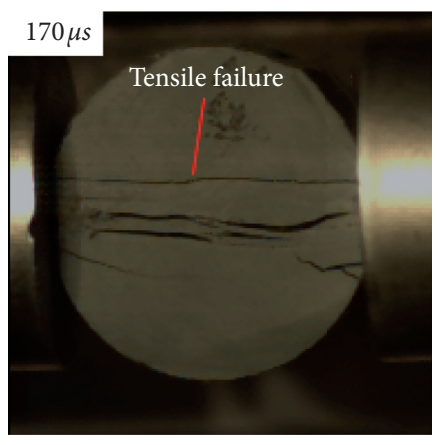

(a)

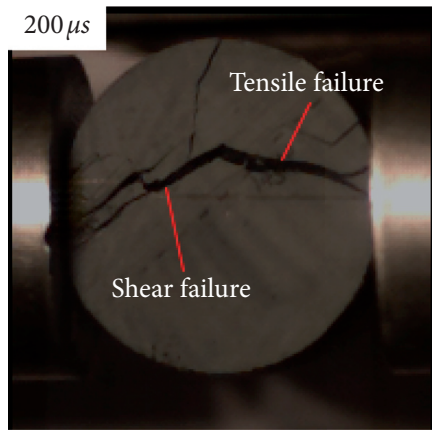

(d)

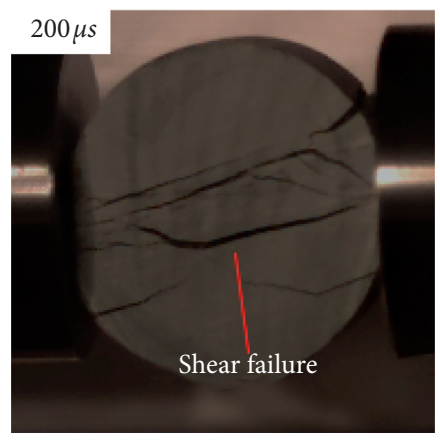

(b)

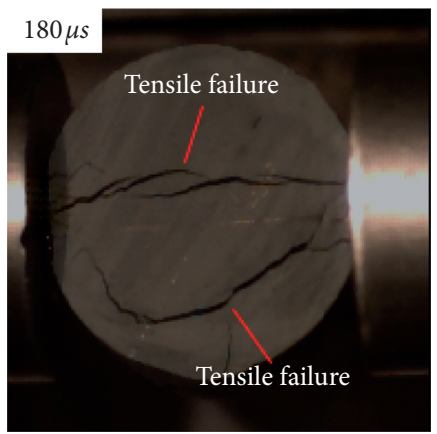

(e)

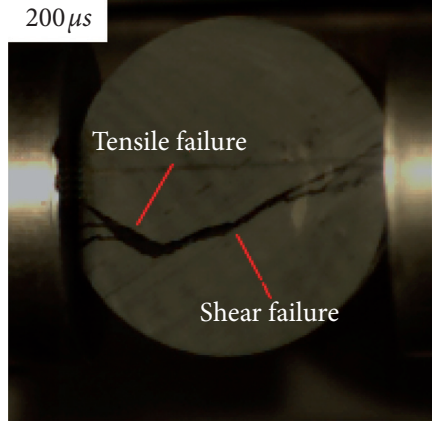

(c)

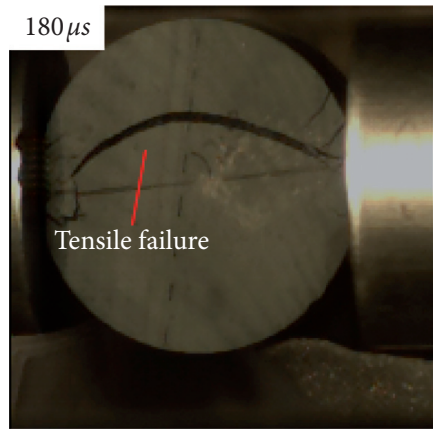

(f)

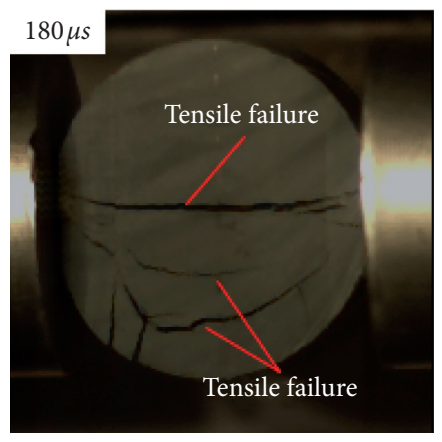

(g)

FIgURE 12: The failure process of the rock disc for the seven tested layer inclination angles by HSC. (a-g) The inclination angles of $0^{\circ}, 15^{\circ}, 30^{\circ}$, $45^{\circ}, 60^{\circ}, 75^{\circ}$, and $90^{\circ}$, respectively. (a) $\beta=0^{\circ}$. (b) $\beta=15^{\circ}$. (c) $\beta=30^{\circ}$. (d) $\beta=45^{\circ}$. (e) $\beta=60^{\circ}$. (f) $\beta=75^{\circ}$. (g) $\beta=90^{\circ}$.

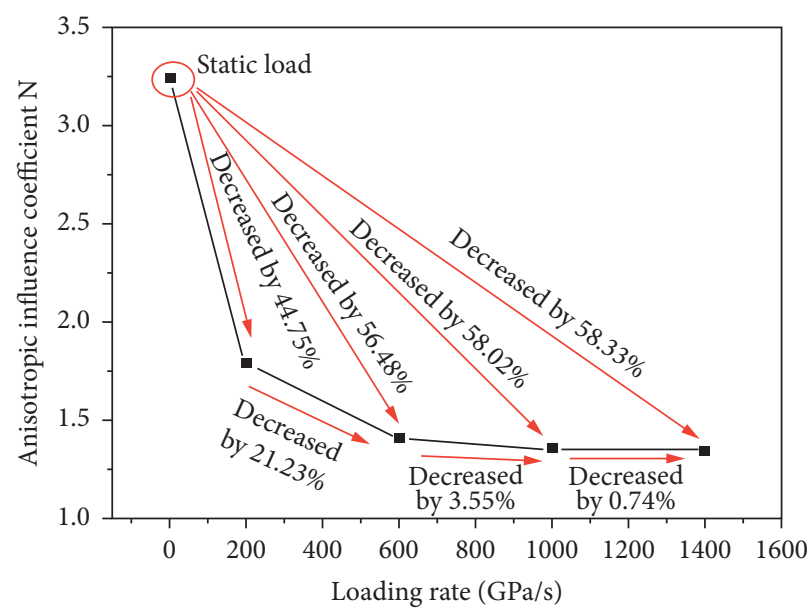

FIgURE 13: The relationship between the anisotropic influence coefficient $\mathrm{N}$ and the loading rate. 


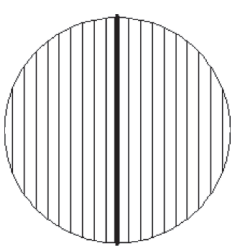

(a)

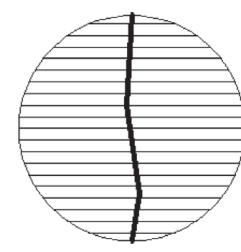

(b)

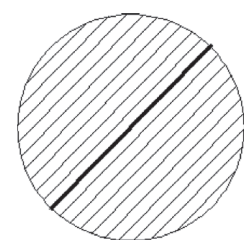

(c)

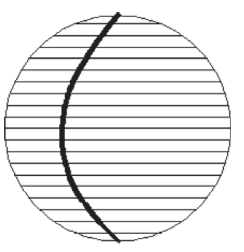

(d)

FIGURE 14: Schematic representation of different fracture types in the Brazilian test. (a) Tensile failure and central fracturing along a bedding plane, (b) tensile failure and central fracturing along a previously intact plane, (c) shear failure and off-centre fracturing along a bedding plane, and (d) tensile failure and noncentral fracturing along a previously intact plane.

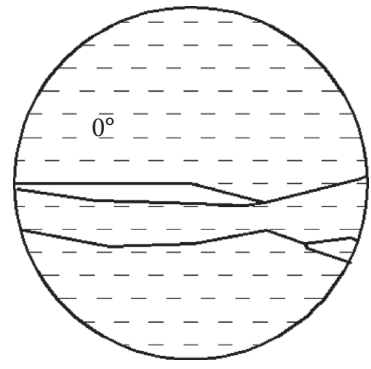

(a)

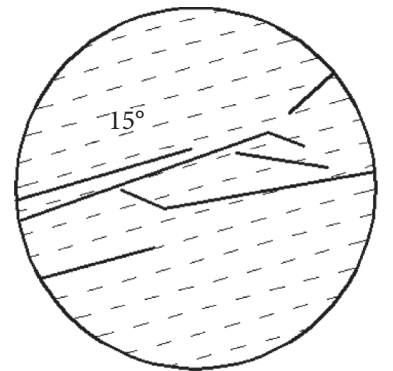

(b)

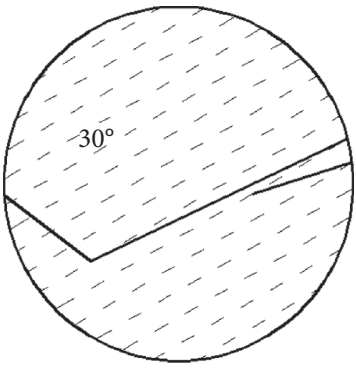

(c)

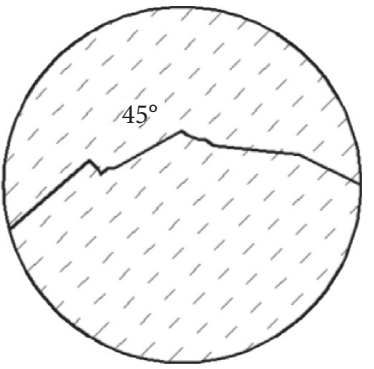

(d)

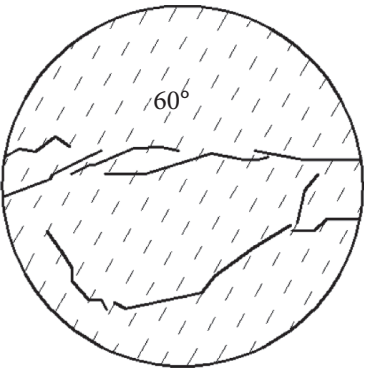

(e)

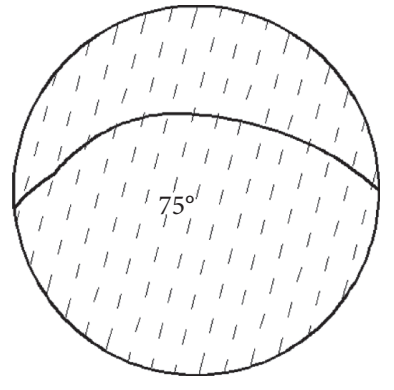

(f)

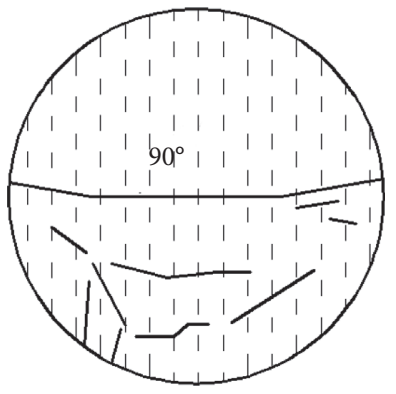

(g)

Figure 15: Failure of the rock disc.

strength. (3) The failure mode of the disc was mainly attributed to failure along the bedding planes when the inclination angle was less than or equal to $45^{\circ}$, and the dynamic failure load obtained by the theoretical calculation was lower. (4) The fracture plane of the disc mainly exhibited tensile failure along the central axis or off-centre when the inclination angle $\beta$ was $60^{\circ}, 75^{\circ}$, or $90^{\circ}$. Sometimes there were two types of mixed failure modes, one along the central axis and another off-centre. In this case, the strength of the tensile failure along the previously intact planes was the highest. (5) The failure mode of the disc was mainly triggered along the centre or off-centre of the disc and previously intact planes when the inclination angle was greater than $45^{\circ}$, and the dynamic tensile strength obtained by the theoretical calculation was greater than the experimental results.

\section{Conclusion}

Using the SHPB system, a thorough investigation of the influence of slate layering on its mechanical properties and failure was carried out in this study. Based on dynamic tensile test results, the mechanical behaviours in terms of the stress-strain relationship and failure load were investigated under the influence of loading rate and bedding angle. The effects of the failure mechanism on the strength distribution law under the influence of included layers were analysed. The main conclusions are highlighted as follows:

(1) As the loading rate increased, the failure load, elastic modulus $E$, and postpeak stress reduction rate $K$ increased under the same inclination angle; the failure load of the discs with the 7 tested bedding angles increased overall. A nonlinear formula was determined for describing the relationship between the loading rate and failure load at the 7 tested inclination angles.

(2) As the inclination angle of the bedding plane increased from $0^{\circ}$ to $90^{\circ}$, both the static and dynamic failure loads of the slate showed an increasing trend. However, as the loading rate increased, the anisotropic influence coefficient $N$ ranged from 3.25 under the static load to 1.35 under the dynamic load, and the bedding effect gradually decreased. When the 
loading rate was increased to a certain value, the bedding effect became negligible.

(3) Under the dynamic Brazilian splitting test, the slate specimens mainly exhibited four failure modes. Sometimes one or two different fracture types occurred in the same experiment. The failure of the disc mainly occurred along the bedding planes, when the inclination angle was less than or equal to $45^{\circ}$. The failure of the disc mainly occurred along the centre or off-centre of the disc and previously intact planes when the inclination angle was greater than $45^{\circ}$.

\section{Data Availability}

No data were used to support this study. The data used in the paper were obtained from the experiment conducted by the authors.

\section{Conflicts of Interest}

The authors declare that they have no conflicts of interest.

\section{Acknowledgments}

This study was funded by the National Natural Science Foundation of China (51704109 and 51604109) and the Hunan Provincial Natural Science Foundation, China (2020JJ5179).

\section{References}

[1] T. Ramamurthy, "Strength and modulus responses of anisotropic rocks," Comprehensive Rock Engineering. Fundamentals, vol. 1, pp. 313-329, Pergamon Press, Oxford, UK, 1993.

[2] B. Amadei, "Importance of anisotropy when estimating and measuring in situstresses in rock," International Journal of Rock Mechanics and Mining Sciences, vol. 33, no. 3, pp. 293-325, 1996.

[3] C.-S. Chen, E. Pan, and B. Amadei, "Determination of deformability and tensile strength of anisotropic rock using Brazilian tests," International Journal of Rock Mechanics and Mining Sciences, vol. 35, no. 1, pp. 43-61, 1998.

[4] Y. M. Tien and M. C. Kuo, "A failure criterion for transversely isotropic rocks," International Journal of Rock Mechanics and Mining Sciences, vol. 38, no. 3, pp. 399-412, 2001.

[5] A. Tavallali and A. Vervoort, "Failure of layered sandstone under Brazilian test conditions: Effect of micro-scale parameters on macro-scale behaviour: Effect of micro-scale parameters on macro-scale behaviour," Rock Mechanics and Rock Engineering, vol. 43, no. 5, pp. 641-653, 2010.

[6] A. Tavallali and A. Vervoort, "Effect of layer orientation on the failure of layered sandstone under Brazilian test conditions," International Journal of Rock Mechanics and Mining Sciences, vol. 47, no. 2, pp. 313-322, 2010.

[7] J.-W. Cho, H. Kim, S. Jeon, and K.-B. Min, "Deformation and strength anisotropy of Asan gneiss, Boryeong shale, and Yeoncheon schist," International Journal of Rock Mechanics and Mining Sciences, vol. 50, pp. 158-169, 2012.

[8] P. L. P. Wasantha, P. G. Ranjith, and S. S. Shao, "Energy monitoring and analysis during deformation of bedded- sandstone: Use of acoustic emission," Ultrasonics, vol. 54, no. 1, pp. 217-226, 2014.

[9] O. Saeidi, V. Rasouli, R. G. Vaneghi, R. Gholami, and S. R. Torabi, "A modified failure criterion for transversely isotropic rocks," Geoscience Frontiers, vol. 5, no. 2, pp. 215225, 2014.

[10] A. Vervoort, K.-B. Min, H. Konietzky et al., "Failure of transversely isotropic rock under Brazilian test conditions," International Journal of Rock Mechanics and Mining Sciences, vol. 70, pp. 343-352, 2014.

[11] S. Y. Wang, C. A. Sloan, W. C. Tang, and W. C. Zhu, "Numerical simulation of the failure mechanism of circular tunnels in transversely isotropic rock masses," Tunnelling and Underground Space Technology, vol. 32, pp. 231-244, 2012.

[12] P. T. Wang, M. F. Cai, and F. H. Ren, "Anisotropy and directionality of tensile behaviours of a jointed rock mass subjected to numerical Brazilian tests," Tunnelling and Underground Space Technology, vol. 73, pp. 139-153, 2018.

[13] D.-P. Xu, X.-T. Feng, D.-F. Chen, C.-Q. Zhang, and Q.-X. Fan, "Constitutive representation and damage degree index for the layered rock mass excavation response in underground openings," Tunnelling and Underground Space Technology, vol. 64, pp. 133-145, 2017.

[14] W. J. Yu, S. H. Du, and W. J. Wang, "Excavation disturbance and stability of short-distance roadway with high stress and soft rock mass," Chinese Journal of Geotechnical Engineering, vol. 36, no. 1, pp. 57-64, 2014.

[15] M. Zhang, H. Shimada, T. Sasaoka, K. Matsui, and L. Dou, "Evolution and effect of the stress concentration and rock failure in the deep multi-seam coal mining," Environmental Earth Sciences, vol. 72, no. 3, pp. 629-643, 2014.

[16] S. K. Bordia, "The effect of size and stress concentration on the dilatancy and fracture of rock," International Journal of Rock Mechanics and Mining Sciences \& Geomechanics Abstracts, vol. 8, no. 6, pp. 629-640, 1971.

[17] Q. Jia and D. R. Schmitt, "Effects of formation anisotropy on borehole stress concentrations: Implications to drilling induced tensile fractures," in Proceedings of the 48th U.S. Rock Mechanics/Geomechanics Symposium, Minneapolis, MN, USA, June 2014.

[18] B. S. Aadnoy and F. Angell-Olsen, "Some effects of ellipticity on the fracturing and collapse behavior of a borehole," International Journal of Rock Mechanics and Mining Sciences \& Geomechanics Abstracts, vol. 32, no. 6, pp. 621-627, 1995.

[19] T. Chakraborty, S. Mishra, J. Loukus, B. Halonen, and B. Bekkala, "Characterization of three Himalayan rocks using a split Hopkinson pressure bar," International Journal of Rock Mechanics and Mining Sciences, vol. 85, pp. 112-118, 2016.

[20] R. D. Perkins, S. J. Green, and M. Friedman, "Uniaxial stress behavior of porphyritic tonalite at strain rates to 103/second," International Journal of Rock Mechanics and Mining Sciences \& Geomechanics Abstracts, vol. 7, no. 5, pp. 527-535, 1970.

[21] Y. X. Zhou, K. Xia, X. B. Li et al., "Suggested methods for determining the dynamic strength parameters and mode-I fracture toughness of rock materials," International Journal of Rock Mechanics and Mining Sciences, vol. 49, pp. 105-112, 2012.

[22] ISRM, "Suggested methods for determining tensile strength of rock materials," International Journal of Rock Mechanics and Mining Sciences, vol. 15, pp. 99-103, 1978.

[23] K. Xia and W. Yao, "Dynamic rock tests using split Hopkinson (Kolsky) bar system-A review," Journal of Rock Mechanics and Geotechnical Engineering, vol. 7, no. 1, pp. 27-59, 2015. 
[24] Q. Z. Wang, W. Li, and H. P. Xie, "Dynamic split tensile test of flattened Brazilian disc of rock with SHPB setup," Mechanics of Materials, vol. 41, no. 3, pp. 252-260, 2009.

[25] P. Wang, J. Xu, X. Fang, M. Wen, G. Zheng, and P. Wang, "Dynamic splitting tensile behaviors of red-sandstone subjected to repeated thermal shocks: Deterioration and micromechanism," Engineering Geology, vol. 223, pp. 1-10, 2017.

[26] X. F. Li, X. Li, H. B. Li, Q. B. Zhang, and J. Zhao, "Dynamic tensile behaviours of heterogeneous rocks: the grain scale fracturing characteristics on strength and fragmentation," International Journal of Impact Engineering, vol. 118, pp. 98-118, 2018.

[27] S. Okubo, K. Fukui, and Q. Qingxin, "Uniaxial compression and tension tests of anthracite and loading rate dependence of peak strength," International Journal of Coal Geology, vol. 68, no. 3-4, pp. 196-204, 2006

[28] K. Xia, S. Huang, and A. K. Jha, "Dynamic tensile test of coal, shale and sandstone using split Hopkinson pressure bar," International Journal of Geotechnical Earthquake Engineering, vol. 1, no. 2, pp. 24-37, 2010.

[29] A. B. Szwilski, "Determination of the anisotropic elastic moduli of coal," International Journal of Rock Mechanics and Mining Sciences \& Geomechanics Abstracts, vol. 21, no. 1, pp. 3-12, 1984.

[30] A. Morcote, G. Mavko, and M. Prasad, "Dynamic elastic properties of coal," Geophysics, vol. 75, no. 6, pp. E227-E234, 2010.

[31] Y. Wang and R. Yang, "Study of the dynamic fracture characteristics of coal with a bedding structure based on the NSCB impact test," Engineering Fracture Mechanics, vol. 184, pp. 319-338, 2017.

[32] F. Dai, R. Chen, M. J. Iqbal, and K. Xia, "Dynamic cracked chevron notched Brazilian disc method for measuring rock fracture parameters," International Journal of Rock Mechanics and Mining Sciences, vol. 47, no. 4, pp. 606-613, 2010.

[33] B. B. Wu, R. Chen, and K. W. Xia, "Dynamic tensile failure of rocks under static pre-tension," International Journal of Rock Mechanics and Mining Sciences, vol. 80, pp. 12-18, 2015. 